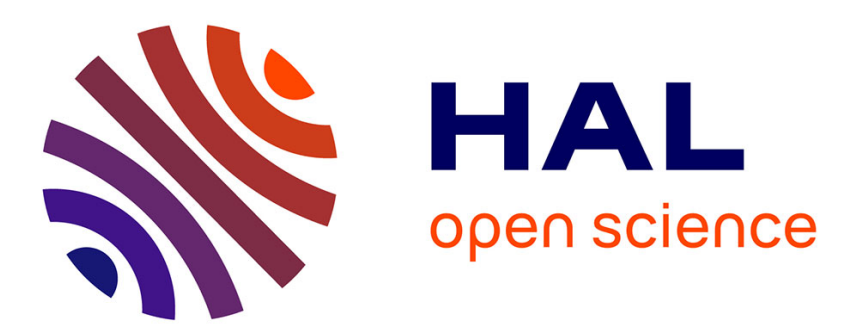

\title{
A practical application approach to argumentation for multicriteria analysis and decision support \\ Rallou Thomopoulos
}

\section{To cite this version:}

Rallou Thomopoulos. A practical application approach to argumentation for multicriteria analysis and decision support. EURO journal on decision processes, 2018, 6 (3-4), pp.237-255. 10.1007/s40070018-0087-2 . hal-01918020v2

\section{HAL Id: hal-01918020 \\ https://hal.science/hal-01918020v2}

Submitted on 22 Feb 2020

HAL is a multi-disciplinary open access archive for the deposit and dissemination of scientific research documents, whether they are published or not. The documents may come from teaching and research institutions in France or abroad, or from public or private research centers.
L'archive ouverte pluridisciplinaire HAL, est destinée au dépôt et à la diffusion de documents scientifiques de niveau recherche, publiés ou non, émanant des établissements d'enseignement et de recherche français ou étrangers, des laboratoires publics ou privés. 


\title{
A Practical Application Approach to Argumentation for Multicriteria Analysis and Decision Support
}

\section{Rallou Thomopoulos}

Received: date / Accepted: date

\begin{abstract}
The paper explores, through an application example, connections between argumentation and another type of methods often involved in decision problems, namely multicriteria analysis. A novel argumentative analysis framework is proposed and applied to assess a short supply chain device for food aid, regarding different categories of criteria. The analysis leads to some feedback concerning argumentation systems.
\end{abstract}

Keywords Argumentation · Application · Decision support · Multicriteria analysis

\section{Introduction}

Making a decision involving several stakeholders with different objectives requires to take into account various types of information: the consequences of each possible decision, the stakeholders' viewpoints and preferences on the decisions, and the indicators they consider as decision criteria. Argumentation [5,25] deals with situations where information is incoherent because it comes from several sources or corresponds to several points of view that possibly have different priority levels. It is a reasoning model based on the construction and evaluation of interacting arguments. It has been formalized both in philosophy and in computer science [19,26,5] and applied to nonmonotonic reasoning (e.g. [11]), decision making (e.g. $[6,12]$ ), for modeling different types of dialogues including negotiation (e.g. $[18,27])$, in deductive argumentation $[2,23]$ and defeasible logic programming [14]. The system introduced in [11] consists of a set of arguments and a binary relation on that set, expressing conflicts among arguments. An argument gives a reason for believing a claim, or for doing an action. Historically, the prototypical application field of argumentation in computer science was the legal domain [24]. More recently, several works proved its relevance in a larger context, in social-related concerns, medicine, food systems, chains, policies and controversies, especially for decision-making purposes [13,10,28, 29,33].

R. Thomopoulos

INRA, IATE joint research unit / INRIA GraphIK

Montpellier, France

Tel.: +33-(0)-499612217

E-mail: rallou.thomopoulos@inra.fr 
Although international research communities are active both in the argumentation and in the decision fields, most often these domains have been studied separately. Several works have proposed attempts to combine both $[16,8,20,15,17,4]$. Applications in agronomy have emerged a few years ago and are growing. Recent works have dealt with the interest of argumentation in decisions about agri-food chain steering [7,30,31]. Among public policy decision problems, agri-food chain arbitrations involve various actors, from production to consumption through processing, distribution and recycling. Consequently, the interests of all the stakeholders of the chain interfere. Given the diversity of their viewpoints, they pursue possibly divergent goals.

In recent food-related concerns, short supply chains [9,21,22] are defined by the close proximity of production to consumption, both geographically and relationally. In 20112012, a food aid association in the South of France experimented with a short supply chain. The aim was to test the feasability of local fruit and vegetable supply for the association, denoted 'AD34'. The analysis of this experimentation examined four criteria: technical, economic, social and participative. A need for explanation, analysis and rationalization of the collected results motivated the approach presented in this paper. Understanding the system involves a high number of interconnected factors that are difficult for a human to grasp. In [31], the relevance of the argumentative approach was highlighted regarding cognitive considerations. In this paper, we revisit argumentation systems to discuss the meaning of notions such as argument acceptability in a concrete case.

Section 2 recalls some elements of argumentation. Section 3 formalizes the short supply case in terms of argumentation systems. Section 4 proposes a novel analysis framework. Section 5 applies this model to the case study and presents the results. Section 6 provides some conclusive feedback and discussion. A very first stage of this study is consultable in [32].

\section{Elements of argumentation systems}

Classically, an argumentation process follows three main steps: (1) constructing arguments and counter-arguments, (2) evaluating the acceptability of the different arguments, and (3) defining the justified conclusions. In Dung's framework [11], to complete the first step, a binary relation on the set of arguments called "attack" is defined, reflecting conflicts among arguments. This section briefly recalls Dung's abstract argumentation framework and mentions some further works based on it.

Definition 1 (Dung's argumentation framework). An argumentation framework is a pair $A F=(A, R)$ where $A$ is a set of arguments and $R \subseteq A \times A$ is an attack relation. An argument $\alpha$ attacks an argument $\beta$ if and only if $(\alpha, \beta) \in R$.

In the above definition, arguments are abstract entities. Their origin and structure are left unknown. Note that we can associate each argumentation system with a directed graph whose nodes are the different arguments, and the edges represent the attack relation between them. Among all the conflicting arguments, one has to define which arguments to keep for inferring conclusions or for making decisions. In [11], different semantics for the notion of acceptability have been proposed. For the purpose of this paper, we only recall admissible and preferred semantics.

Definition 2 (Conflict-free, Defense, Admissibility). Let $B \subseteq A$.

- $B$ is conflict-free if and only if $\nexists \alpha_{i}, \alpha_{j} \in B$ such that $\left(\alpha_{i}, \alpha_{j}\right) \in R$; 
- $B$ defends an argument $\alpha_{i} \in B$ if and only if for each argument $\alpha_{j} \in A$, if $\left(\alpha_{j}, \alpha_{i}\right) \in R$, then $\exists \alpha_{k} \in B$ such that $\left(\alpha_{k}, \alpha_{j}\right) \in R$;

- a conflict-free set $B$ of arguments is admissible if and only if $B$ defends all its elements.

From the definition of an admissible set, several semantics have been introduced to define coherent sets of arguments, called extensions. For the purposes of this paper, we only recall the preferred semantics. It is given in Definition 3, together with the acceptability status of arguments (skeptically/credulously accepted, or rejected). We also introduce the notion of "strictly credulously accepted" argument, used in the rest of the paper.

Definition 3 (Preferred semantics and argument acceptability). A preferred extension is a maximal (with respect to set inclusion) admissible set of arguments.

An argument is said to be:

- skeptically accepted if it is in all extensions;

- credulously accepted if it is in at least one extension;

- strictly credulously accepted if it is credulously accepted and not skeptically accepted;

- rejected if it is not in any extension.

The sets of skeptically accepted, credulously accepted, strictly credulously accepted and rejected arguments are respectively denoted Skept, Cred, SCred and Rej. We have SCred = Cred $\backslash$ Skept.

\section{Problem formalization}

\subsection{The experimental device}

The partners involved in the short food chain experimentation (also referred to as the 'device') were the AD34 association, the managers of the National Wholesale Market (MIN), and the "Innovation" French joint research team. In a first stage, the criteria to be analyzed in the study were defined: technical (logistic), economic (added value for producers and wholesalers), social (relations and the sharing of information between stakeholders) and participative (involvement of the actors). In a second stage, information was collected: semi-structured interviews were conducted with producers participating in the device (10 interviews with 8 producers), groupings of producers, coordinators of the agri-food networks in MIN (4 interviews), the two wholesalers (4 interviews), the volunteers responsible for receiving the fruit and vegetables from AD34's warehouse (4 interviews), and other AD34 volunteers (10 interviews with 10 volunteers responsible for the distribution centers). By the end of the campaign, surveys were conducted with volunteers at the distribution centers (response rate of $77 \%$ covering 56 volunteers) and recipients of the food aid (122 people answered, from a sample of 10 representative centers), essentially concerned with the technical criterion.

\subsection{Formalizing arguments and attacks}

From the surveys conducted in the way presented in the previous section, the various arguments put forward by the different stakeholders were collected and organized. Then, the argument analysis was performed in five steps: 
- the main arguments in favor ('pro') and against ('con') the experimental device were identified;

- arguments were refined and structured in argument/decision tables which establish a link with the decisions (support or oppose the device, corresponding to 'pro' and 'con' arguments respectively) that the involved actors may make. In this step, the hypothesis and conclusion parts of each argument were identified, as depicted in Table 1 in the "Description" column (the hypothesis is in italic, the conclusion is underlined). We may also need to express refinements of a given argument. For example in Table 1 after Argument B we see two arguments, C and D, refining it with more specialized hypotheses: "nonstandard' (in Argument C) and 'overproduction' (in Argument D) provide sub-cases of 'hard to sell' (in Argument B). This will play a role in the attack definition;

- attacks are then defined based on logical contradiction. It is not the aim of this paper to introduce a logical framework. Interested readers may refer for instance to $[31,28]$ for logical approaches in practical applications. As a brief propositional-logic illustration, in Table 1 we have priceLoss $\rightarrow \neg$ wellAccepted (Argument A) and hardToSell $\wedge$ priceLoss $\rightarrow$ wellAccepted (Argument $\mathrm{B}$ ), therefore $(B, A) \in R$. This step implies a terminological homogenization, for instance 'no price loss' and 'lower prices' are considered as synonyms;

- the contents of the argument/option tables were displayed in the form of argumentation graphs that can be evaluated according to the method of [11];

- finally, we analysed the selected argumentation graph in the light of the analytical model introduced in this paper (Sections 4 and 5).

Several groups of arguments were identified. The first group (see Table 1) examines which food products were likely to lead to the success or failure of the device and why.

\begin{tabular}{|c|c|c|c|}
\hline Arg. & Description: Hypothesis, Conclusion & Decision & Criterion \\
\hline $\mathrm{A}$ & $\begin{array}{l}\text { the device is well accepted only when it induces no price loss } \\
\text { for producers compared to the classical system }\end{array}$ & pro & economic \\
\hline $\mathrm{B}$ & $\begin{array}{l}\text { the device requires little effort for producers and succeeds even } \\
\text { with lower prices for products that are hard to sell in the } \\
\text { classical system }\end{array}$ & pro & economic \\
\hline $\mathrm{C}$ & $\begin{array}{l}\text { the device succeeds with lower prices for non-standard products, } \\
\text { which are hard to sell in the classical system }\end{array}$ & pro & economic \\
\hline $\mathrm{D}$ & $\begin{array}{l}\text { the device succeeds with lower prices for overproduction due to } \\
\text { climatic reasons, which is hard to sell in the classical system since } \\
\text { it leads to an imbalance between supply and demand }\end{array}$ & pro & economic \\
\hline $\mathrm{E}$ & $\begin{array}{l}\text { the device failed when it turned out to be too adverse compared } \\
\text { to the classical system }\end{array}$ & con & economic \\
\hline
\end{tabular}

Table 1 Arguments about the interest of the device (first series)

We can notice that arguments $\mathrm{C}$ and $\mathrm{D}$ are particular cases of $\operatorname{argument} \mathrm{B}$, and that the three of them (B, C, D) disagree with argument A since they express that price is not the only element that may lead to the success of the device. Thus we can note that the attack relation $R$ contains the following attacks: (B, A), (C, A), (D, A).

Argument E, which is less detailed than the previous ones since it only mentions "adverse" conditions without more precise elements (price, etc.), expresses no contradiction with the previous arguments, although it is expressed as a negative argument. However it is refined by the following new arguments, given in Table 2 .

Argument $\mathrm{F}$ is counterbalanced by the arguments listed in Table 3. 


\begin{tabular}{|l|l|l|l|}
\hline Arg. & Description & Decision & Criterion \\
\hline F & the device failed when it was too adverse in terms of price & con & economic \\
\hline G & $\begin{array}{l}\text { the device failed when it was too adverse in terms of storage } \\
\text { capacity }\end{array}$ & con & technical \\
\hline
\end{tabular}

Table 2 Arguments about the interest of the device (second series)

\begin{tabular}{|c|c|c|c|}
\hline Arg. & Description & Decision & Criterion \\
\hline $\mathrm{H}$ & $\begin{array}{l}\text { the device was a success even with low prices when it took } \\
\text { place in a context of low demand, combined with an advantage } \\
\text { for producers }\end{array}$ & pro & economic \\
\hline $\mathrm{I}$ & reduced transportation cost is a possible advantage & pro & economic \\
\hline $\mathrm{J}$ & $\begin{array}{l}\text { the sale of non-standard (e.g. large-size) products is a possible } \\
\text { advantage }\end{array}$ & pro & economic \\
\hline $\mathrm{K}$ & $\begin{array}{l}\text { motivation to participate in a solidarity project is a possible } \\
\text { advantage }\end{array}$ & pro & participative \\
\hline $\mathrm{L}$ & $\begin{array}{l}\text { keeping good business contacts with the wholesalers is a } \\
\text { possible advantage }\end{array}$ & pro & social \\
\hline
\end{tabular}

Table 3 Arguments about the interest of the device (third series)

Arguments I, J, K, L are different variations of argument $\mathrm{H}$. In this set $\{\mathrm{H}, \mathrm{I}, \mathrm{J}, \mathrm{K}, \mathrm{L}\}$, all arguments contradict with the prior argument $\mathrm{F}$. Thus we can add the following attacks to the attack relation $R$ : $(\mathrm{H}, \mathrm{F}),(\mathrm{I}, \mathrm{F}),(\mathrm{J}, \mathrm{F}),(\mathrm{K}, \mathrm{F}),(\mathrm{L}, \mathrm{F})$.

Finally, the technical and social arguments provided in Table 4 complete the above description. We can notice several oppositions related to these last five arguments. Indeed, argument $\mathrm{N}$ is a counter-example of argument $\mathrm{M}$ based on a social benefit of the device. Thus we can add to the attack relation $R:(\mathrm{N}, \mathrm{M})$.

\begin{tabular}{|l|l|l|l|}
\hline Arg. & Description & Decision & Criterion \\
\hline M & $\begin{array}{l}\text { the device failed when it did not take into account the quantities } \\
\text { available on the local market }\end{array}$ & con & technical \\
\hline N & $\begin{array}{l}\text { for some products, the device was a success despite the } \\
\text { inadequacy of the planned dates to the reality of the local } \\
\text { market, thanks to the wholesalers' good knowledge of the local } \\
\text { market, leading to a new planning proposition }\end{array}$ & pro & social \\
\hline O & $\begin{array}{l}\text { large-size products brought logistical difficulties to the } \\
\text { volunteers of the distribution centers }\end{array}$ & con & technical \\
\hline P & $\begin{array}{l}\text { local fresh products facilitated the volunteers' work from a } \\
\text { logistical viewpoint, by avoiding them to sort damaged } \\
\text { products }\end{array}$ & pro & technical \\
\hline Q & the disposal of products was achieved in reduced time & pro & technical \\
\hline
\end{tabular}

Table 4 Arguments about the interest of the device (fourth series)

Argument $\mathrm{O}$ mentions a technical difficulty associated with large-size products. This contrasts with argument $\mathrm{J}$ which considers the handling of non-standard products as a positive feature of the device. It also contrasts with argument A, which tends to reduce to price issues the difficulties encountered by the device. Thus the following attacks can be added to $R:(\mathrm{O}, \mathrm{A}),(\mathrm{O}, \mathrm{J})$.

Moreover, arguments $\mathrm{O}$ and $\mathrm{P}$ both focus on logistical aspects of the device. $\mathrm{O}$ is a negative one, since it addresses the necessity of cutting large-size products, which is not only time-consuming but also implies space and equipment to do it. On the opposite, $\mathrm{P}$ is a 
positive aspect, since the sorting of damaged products can be avoided in the device. Thus a mutual attack between $\mathrm{O}$ and $\mathrm{P}$ is declared in $R:(\mathrm{O}, \mathrm{P}),(\mathrm{P}, \mathrm{O})$.

Finally, argument $\mathrm{P}$ highlights waste reduction, which counterbalances the economic argument $\mathrm{F}$. Thus we can add to the attack relation $R:(\mathrm{P}, \mathrm{F})$.

The full argumentation graph is given in Figure 1.

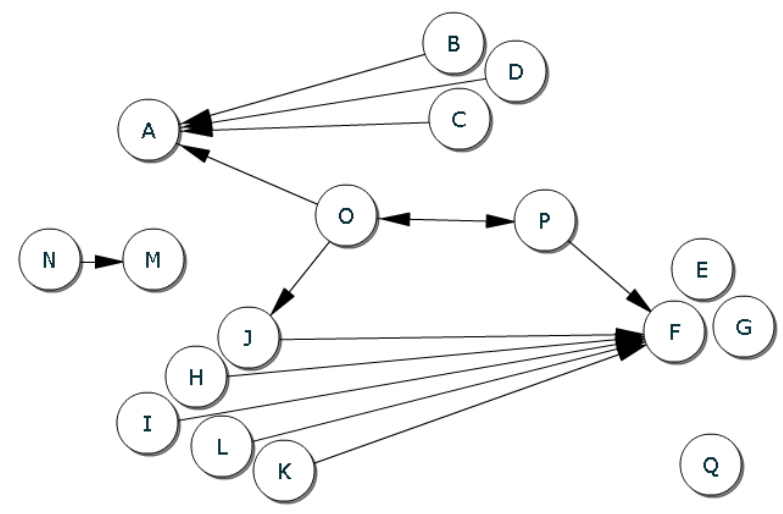

Fig. 1 Graph of arguments and attacks

Figures 2 and 3 display the two preferred extensions (see Definition 3) of this argumentation system. The arguments displayed in green (light grey in case of black and white display) belong to the extension, those in red (dark grey in case of black and white display) do not. An immediate remark that can be noted is that there is more than one extension, here two extensions which correspond to coherent sets of arguments. Thus there are divergences in the system that led to these two viewpoints.

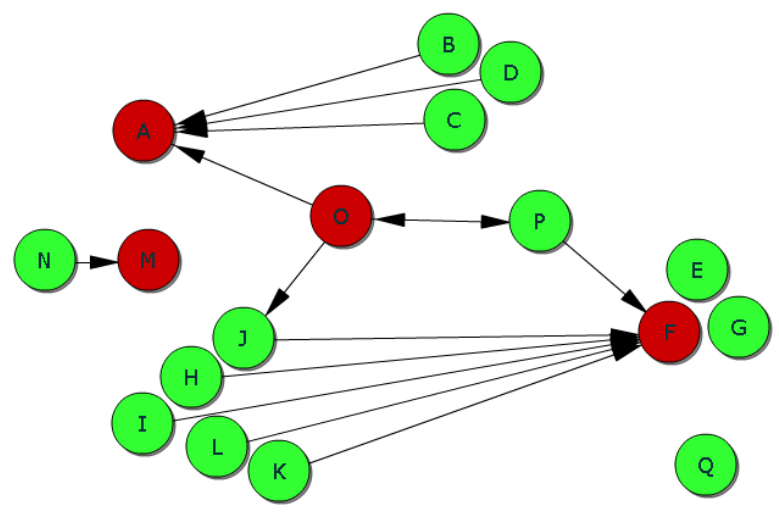

Fig. 2 First preferred extension

There are three rejected arguments. These are the arguments that belong to no extension. Technically, they appear in red (dark grey) both in Figures 2 and 3. They are, namely, A, F, 


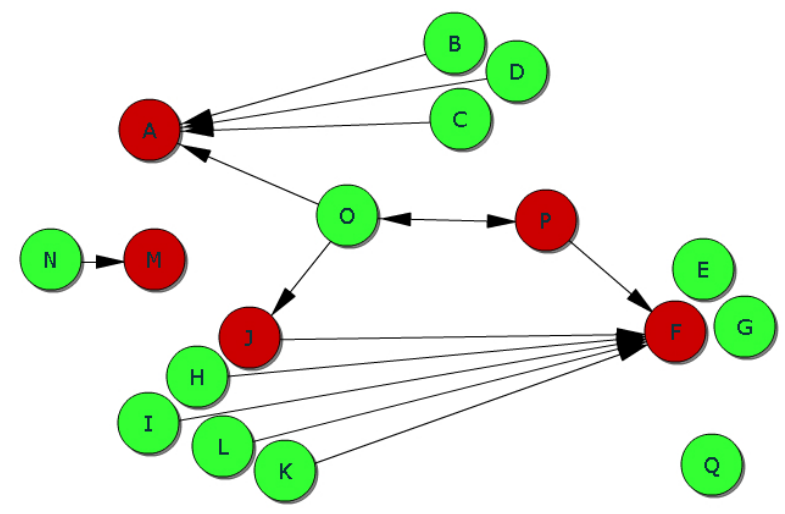

Fig. 3 Second preferred extension

and M. Thus $R e j=\{A, F, M\}$. Apart from these three arguments, the rest of the arguments are credulously accepted.

Three other arguments belong to one extension but not to both. These are the strictly credulously accepted arguments, namely $\mathrm{O}$ - in green (light grey) in Figure 2 but not 3 as well as $\mathbf{J}$ and $\mathbf{P}$ - in green (light grey) in Figure 3 but not 2. This means that, to adopt a coherent point of view, one has to choose between either $\mathrm{O}$, or the pair $\{J, P\}$. Thus we have $S C r e d=\{J, O, P\}$.

The remaining arguments belong to both extensions: they appear in green (light grey) both in Figures 2 and 3. They are skeptically accepted and thus form Skept.

Figure 4 synthesizes the acceptability of arguments. Arguments belonging to $R e j$ are depicted with a black dash, arguments of SCred with a grey dash, arguments of Skept are white (with no dash). Cred is the union of SCred and Skept.

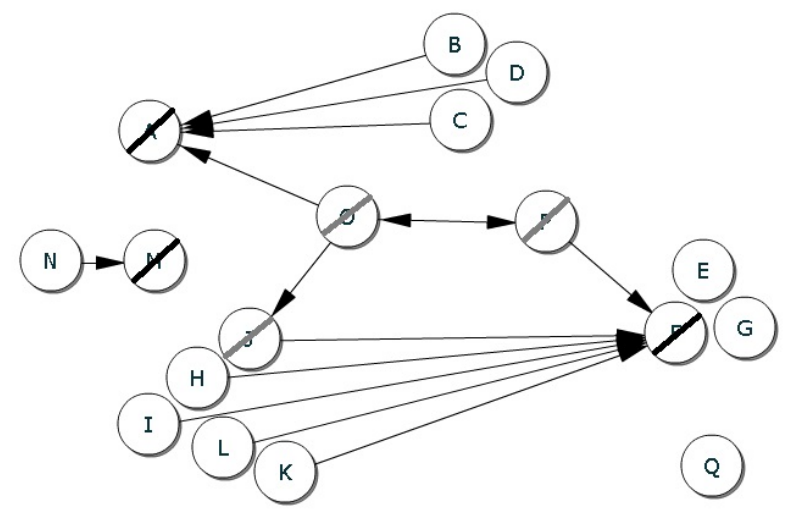

Fig. 4 Argument acceptability

At this stage, we lack of features to analyze these divergences. Indeed, we would expect from the argumentation system to provide explanations about the origin of the discordances 
that led to different viewpoints, highlighted by the existence of several extensions. These explanations could be provided by tracing not only the conflicting arguments, but also the criteria and rationale they rely on. To go further we need to use the analytical argumentation system $A A S$ and the indicators presented in next section.

\section{The proposed analysis framework}

This section introduces a model denoted analytical argumentation system together with several indicators. It includes several ways of organizing the set of arguments in contexts. Each way provides a partition of $A$.

Definition 4 (Analytical Argumentation System). An Analytical Argumentation System is a tuple $A S S=\left(A ; R ; C_{1} \ldots C_{n}\right)$ where:

- $A$ is a set of arguments;

$-R \subseteq A \times A$ is an attack relation;

- each $C_{i}$ is a partition of $A$. It is thus a breakdown of the set of arguments $A$ into subsets called contexts. By definition of a partition: $\left(\bigcup_{c \in C_{i}} c=A\right)$ and $\left(\bigcap_{c \in C_{i}} c=\varnothing\right)$.

We may note that the case $n=0$ corresponds to the classic Dung system. The case $n=$ 1 reminds of the $C P A F$ model [3], without preference relations, though. Indeed, among the various works that were proposed in order to enhance the expressivity of argumentation systems, some envisaged contexts as a way to equip argumentation systems with multiple non-conflicting preference relations [3,7]. However, in the present work, we are interested in structuring the set of arguments $A$ without expressing any value judgement regarding the relative importance of arguments. Consequently the framework we propose does not include preferences. Indeed, the introduction of contexts has another purpose here, providing several ways to categorize the arguments.

Several indicators are then associated with the AAS in order to make an analysis.

Definition 5 (Indicators). Given an Analytical Argumentation System $A S S=\left(A ; R ; C_{1}\right.$ $\left.\ldots C_{n}\right)$, let Rej, Skept, Cred and SCred denote respectively the set of rejected, skeptically accepted, credulously accepted and strictly credulously accepted arguments in $(A, R)$ (see Definition 3). The following indicators are computed:

- Indicators concerning the polemical status of the system:

- Ratio of rejected arguments: $|\operatorname{Rej}| /|A| \in[0 ; 1]$;

- Number and proportion of rejected arguments per context. For each context $c$ :

- the number of rejected arguments is computed as $|\{a \in \operatorname{Rej} \bigcap c\}|$;

- the proportion of rejected arguments is computed as $|\{a \in \operatorname{Rej} \bigcap c\}| /|c|$.

- Number of internal and external attacks towards rejected arguments, per context. For each context $c$ :

- the number of internal attacks is computed as $\mid\left\{\left(a_{i}, a_{j}\right) \in R, a_{i} \in c, a_{j} \in\right.$ $\operatorname{Rej} \cap c\} \mid$

- the number of external attacks is computed as $\mid\left\{\left(a_{i}, a_{j}\right) \in R, a_{i} \in A \backslash c, a_{j} \in\right.$ $\operatorname{Rej} \cap c\} \mid$.

- Indicators concerning the origin of divergent viewpoints:

- Ratio of skeptically versus credulously accepted arguments: $\mid$ Skept $|/|$ Cred $\mid \in[0 ; 1]$;

- Number and proportion of strictly credulously accepted arguments per context. For each context $c$ : 
- the number of strictly credulously accepted arguments is computed as $\mid\{a \in$ SCred $\bigcap c\} \mid$

- the proportion of strictly credulously accepted arguments is computed as $\mid\{a \in$ SCred $\bigcap c\}|/| c \mid$.

- Number of internal and external attacks towards strictly credulously accepted arguments, per context. For each context $c$ :

- the number of internal attacks towards strictly credulously accepted arguments is computed as $\left|\left\{\left(a_{i}, a_{j}\right) \in R, a_{i} \in c, a_{j} \in \operatorname{SCred} \bigcap c\right\}\right|$;

- the proportion of external attacks towards strictly credulously accepted arguments is computed as $\left|\left\{\left(a_{i}, a_{j}\right) \in R, a_{i} \in A \backslash c, a_{j} \in \operatorname{SCred} \bigcap c\right\}\right|$.

In the following we explain the rationale of these indicators.

Indicators concerning the polemical status of the system.

\section{- Ratio of rejected arguments.}

Rejected arguments are those that are attacked and not defended, thus belonging to none of the extensions and defined as not acceptable. Beyond this concept, there is the idea that these arguments are not reliable, since they receive non-countered attacks. However, as illustrated by the case study in the following, these arguments can express first rough ideas or biases that serve as initial pillars which are then criticized, refined and thus rejected afterwards. They can be of great importance for the construction of the argumentation system. The ratio of rejected arguments informs about the extent to which the situation is polemical. Note that rejected arguments are, in a sense, consensual, since all the viewpoints that emerged agree to reject them.

- Number and proportion of rejected arguments per context.

Since a partition is a breakdown of the set of arguments in different contexts (for example, the criteria studied, the decisions supported, the authors of the arguments, etc.), it is important to note that contexts are angles of analysis. They are different from extensions, which bring together coherent arguments, possibly from different contexts.

Basic statistics about the repartition of the rejected arguments in the different contexts of a partition (number and proportion of rejected arguments per context) provides information about the contexts that are the more subject to polemic. The higher these indicators, the more polemical the context is, in a given partition.

- Number of internal and external attacks towards rejected arguments.

Finally, in a given partition, rejected arguments can be further analyzed by determining the number and the ratio of "internal" attacks, i.e. attacks from arguments of the same context, and "external" attacks, i.e. from arguments of other contexts (and which of them in particular). These indicators inform on the nature of the polemic, whether it stems from similar or from other types of considerations than those of the rejected arguments.

\section{Indicators concerning the origin of divergent viewpoints.}

- Ratio of skeptically versus credulously accepted arguments $(\mid$ Skept $|/|$ Cred $\mid \in[0 ; 1])$. Skeptically accepted arguments are those that are accepted in all the extensions, that is to say, in all coherent sets of arguments, which can be interpreted as viewpoints. They represent arguments that, whatever the viewpoint, are not attacked or, if they are attacked, are defended in all viewpoints. They are thus consensual arguments. 
Credulously accepted arguments are accepted in some extensions, at least one, but not necessarily in all of them. The ratio of skeptically versus credulously accepted arguments measures the balance between consensual and dividing arguments. The closer to 1 , the more consensual the situation. The closer to 0 , the more divided the situation. Arguments that are not accepted in all extensions, i.e. credulously but not skeptically accepted, are incompatible with some arguments in the other viewpoints. As stated in Definition 3, we denote these arguments "strictly credulously accepted arguments". They are thus defined as the elements of Cred $\backslash$ Skept. They correspond to arguments about which a choice had to be made when adopting a viewpoint. These arguments correspond to divergences in the opinions.

- Number and proportion of strictly credulously accepted arguments per context. To understand the origin of divergent viewpoints, strictly credulously accepted arguments are key features, since they constitute the differences between viewpoints. Strictly credulously accepted arguments are in conflict with some arguments of the system, but supported by others. The number and proportion of strictly credulously accepted arguments in each context of a partition provides information about the contexts that are involved in divergences. The higher these indicators, the more divergences about the context, in a given partition.

- Number of internal and external attacks towards strictly credulously accepted arguments.

In a given partition, strictly credulously accepted arguments can be further analyzed by determining the number and the ratio of "internal" attacks, i.e. attacks from arguments of the same context, and "external" attacks, i.e. from arguments of other contexts (and which of them in particular). These indicators inform on the nature of discordances, whether they stem from similar or from other types of considerations than those of the strictly credulously accepted arguments.

The use of these indicators is illustrated on the case study in the following section.

\section{Analysis of the device through the analytical argumentation framework}

This section proposes an analysis and feedback of the experimental device based on the $A A S$ framework. An analytical argumentation system $A A S=(A ; R ; C 1 ; C 2)$ is instantiated with the following elements:

- $A$ is composed of the arguments from A to Q described in Section 3.2;

$-R$ is composed of the attacks indicated in Section 3.2;

- two partitions are defined:

- according to the criteria studied in the device, thus $C 1=\{$ economic context, technical context, participative context, social context $\}$;

- according to the aspects, favorable ('pro') or unfavorable ('con') to the device, of the arguments, thus $C 2=\{$ 'pro' context, 'con' context $\}$.

In the following, we review the two families of indicators proposed in Definition 5.

Indicators concerning the polemical status of the system.

- Ratio of rejected arguments. 
3 arguments out of 17 are rejected. The ratio of rejected arguments is thus 0.18 , which means that a minority of arguments (18\%) are attacked without being defended. One could think that these are weak arguments that are not receivable. However, looking into the content of these arguments shows that they appeal to common sense. The first two arguments (A and F) express that the device has to be economically viable to be of interest, the third one (M) claims it has to be aware of the market quantities. The three of them recommend a practical view of the market reality, and are far from being nonsense. However, these arguments need to be refined, examined with particular situations showing they could be overcome. That was the role of the experimental device, and the reason why these arguments were rejected.

In summary, the system shows a moderate polemic linked to the refinement of initial common-sense arguments about consideration of the market reality.

- Number and proportion of rejected arguments per context.

In order to further understand the sources of polemic and divergences, let us now display the system according to the partition $C 1$ proposed in the analytical argumentation system AAS. Figures 5 and 6 show the two preferred extensions partitioned according to $C 1$. Figures 7 and 8 show the two preferred extensions partitioned according to $C 2$. The contexts of $C 1$ contain, respectively, 9, 5, 1 and 2 arguments, showing the prevalence of economic and technical motivations. The contexts of $C 2$ contain, respectively, 12 and 5 arguments, highlighting the amount of opinions expressed in support to the device.

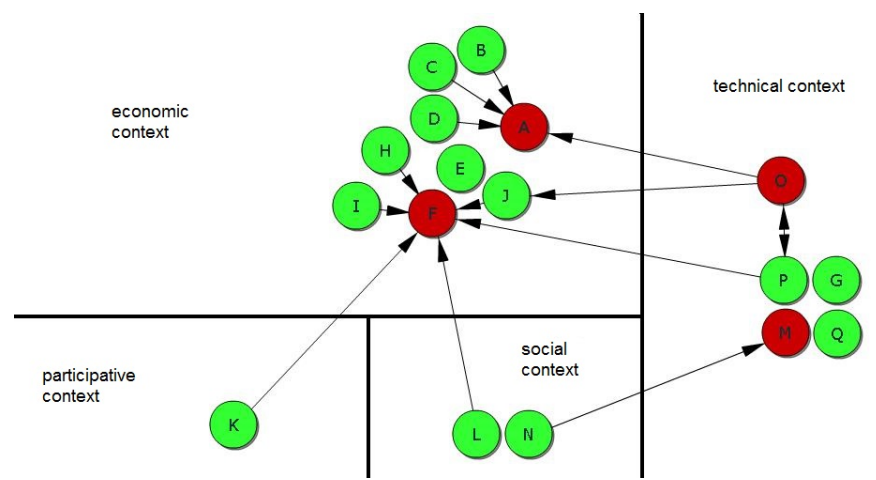

Fig. 5 First preferred extension partitioned according to $C 1$ (the contexts are the criteria of the study)

In $C 1=$ \{economic context, technical context, participative context, social context $\}$, the numbers of rejected arguments per context are respectively 2, 1, 0 and 0 , and their proportions $22 \%, 20 \%, 0 \%$ and $0 \%$. We can conclude that the polemic mainly regards economic concerns, and secondarily technical concerns. Indeed, among the rejected arguments, A and $\mathrm{F}$ deal with prices, whereas $\mathrm{M}$ deals with market quantities.

In $C 2=$ \{'pro' context, 'con' context $\}$, the numbers of rejected arguments per context are respectively 1 and 2 and their proportions $8 \%$ and $40 \%$. We can see that the "unfavorable context" in $C 2$ concentrates rejected arguments. They represent $40 \%$ of this context. This is not surprising, since the initial arguments, which were refined and rejected by the experimental device, were not in favor of the device. The device had to prove it had a chance to work, despite the initial unfavorable arguments.

- Number of internal and external attacks towards rejected arguments. 


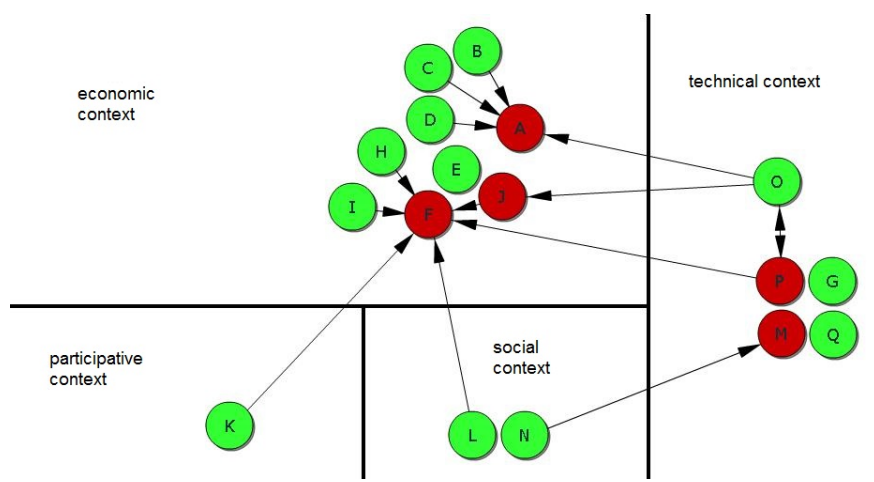

Fig. 6 Second preferred extension partitioned according to $C 1$ (the contexts are the criteria of the study)

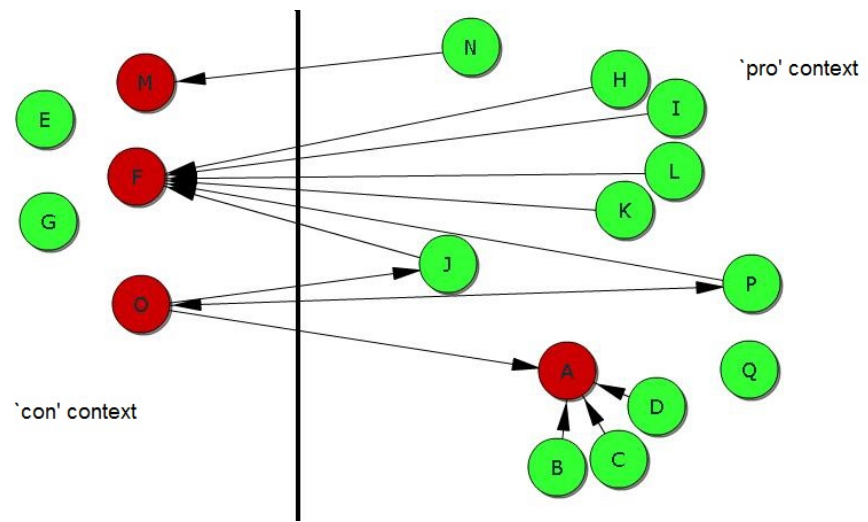

Fig. 7 First preferred extension partitioned according to $C 2$ (the contexts are the 'pro' or 'con' options supported by the arguments)

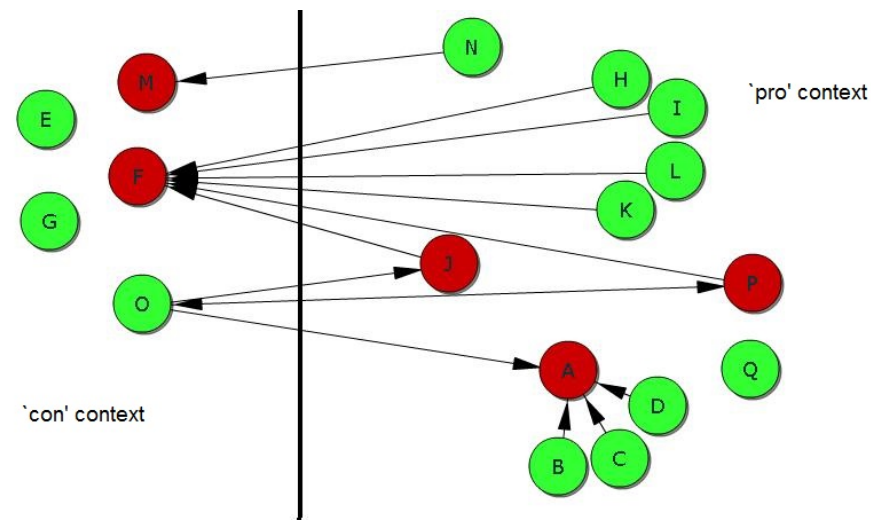

Fig. 8 Second preferred extension partitioned according to $C 2$ (the contexts are the 'pro' or 'con' options supported by the arguments)

In $C 1=$ \{economic context, technical context, participative context, social context $\}$, the numbers of internal attacks (i.e. from the same context) towards rejected arguments (i.e. A, 
F, M) are respectively 6, 0, 0 and 0 , and the numbers of external attacks (i.e. from other contexts) are 4, 1, 0 and 0 .

It may be surprising to note that the economic arguments are mainly internally attacked by other economic arguments, which tends to demonstrate that initial reluctances to consider a possible economic viability of the device had to be revised in the light of the practical implementation of the device and specific conditions (e.g. re-duced transportation cost, context of low demand, etc.). External attacks to the economic arguments are quite balanced between the different other contexts ( 2 from the technical context, 1 from the participative context, 1 from the social context). Their meaning is that economic drawbacks can be counterbalanced by benefits in other concerns (e.g. keeping good business contacts with wholesalers, as expressed by the social argument L). It is worth noticing that the social context, although composed only of 2 arguments, is highly involved in the polemic against rejected arguments, since both social arguments attack a rejected argument. For instance, the technical rejected argument is only attacked by a social one.

In $C 2=\{$ 'pro' context, 'con' context $\}$, the numbers of internal attacks are respectively 3 and 0 , and the numbers of external attacks are 1 and 7.

These figures show that the attacks to the rejected arguments essentially came from arguments favorable to the device, whether or not the rejected arguments were themselves favorable. This is understandable, since the attacks can have different meanings: either a refinement of a 'pro' argument such as A, or a contradiction to a 'con' argument such as F or M.

Indicators concerning the origin of divergent viewpoints.

- Ratio of skeptically versus credulously accepted arguments.

14 arguments are credulously accepted, among which 11 are skeptically accepted. The ratio of skeptically versus credulously accepted arguments is 0.79 , which ex-presses a rather consensual debate ( $79 \%$ consensual), although a $21 \%$ divergence remains. As mentioned above, this divergence is due to the three arguments that are strictly credulously accepted ( $\mathrm{J}, \mathrm{O}$ and $\mathrm{P}$ ). The divergence regards two points: (i) whether or not the sale of non-standard size products is a possible advantage, with a divergence between $\mathrm{J}$ and $\mathrm{O}$, and (ii) whether the device brings logistic advantage, with a divergence between $\mathrm{O}$ and $\mathrm{P}$.

- Number and proportion of strictly credulously accepted arguments per context.

In $C 1=$ economic context, technical context, participative context, social context $\}$, the numbers of strictly credulously accepted arguments per context are respectively 1, 2, 0 and 0 , and their proportions $11 \%, 40 \%, 0 \%$ and $0 \%$. We can conclude that the technical context plays an important part in divergences. Indeed, among the strictly credulously accepted arguments, $\mathrm{O}$ and $\mathrm{P}$ are technical and deal with logistical issues, whereas $\mathrm{J}$ considers the device as an economic opportunity for non-standard products.

In $C 2=\{$ 'pro' context, 'con' context $\}$, the numbers of strictly credulously accepted arguments per context are respectively 2 and 1, and their proportions $17 \%$ and $20 \%$. These similar proportions express that divergences in viewpoints are balanced between favorable or unfavorable opinions regarding the device.

- Number of internal and external attacks towards strictly credulously accepted arguments. 
In $C 1=$ \{economic context, technical context, participative context, social context $\}$, the numbers of internal attacks (i.e. from the same context) are respectively $0,2,0$ and 0 , and the numbers of external attacks (i.e. from other contexts) are 1, 0, 0 and 0 . These figures provide important information: divergences in viewpoints are all related to technical considerations. Indeed, there are no internal discordances except for the technical context, which has an internal dilemma about the logistical benefit of the device (arguments $\mathrm{O}$ and $\mathrm{P}$ ). Moreover, there is only one external attack directed against the economic argument, and this attack is again coming from the technical context (argument $\mathrm{O}$ ). Thus the technical argument $\mathrm{O}$ appears to be a backbone of the divergences expressed in the system.

In $C 2=\{$ 'pro' context, 'con' context $\}$, the numbers of internal attacks are respectively 0 and 0 , and the numbers of external attacks are 2 and 1 . Unsurprisingly we can conclude on a dichotomy between favorable and unfavorable arguments, since in this partition there are no internal divergences. All of them stem from the opposite context.

\section{Conclusion}

This paper introduced a novel analysis framework based on argumentation, called Analytical Argumentation System, presented its application to evaluate an innovative experimentation of a short food supply chain and analysed the results obtained regarding the controversial aspects of the experimental device. This model uses contexts and defines several indicators to evaluate the system studied.

The analysis led to the following main feedback:

- Rejected arguments are not to be interpreted as non-receivable, but rather as rough ideas that needed to be refined. The idea that rejected arguments are not reliable, is not validated by the study, since they show to be initial pillars of great importance for the construction of the argumentation system. This corroborates results obtained in previous studies, such as [7] where the argument supporting a nutritional recommendation by the Ministry of Health was attacked on all sides as a defensive response. On the contrary, in different types of applications such as in big data analysis, social networks, etc., the number and structure of attacks to an argument may be relevant indicators of its strength [1], which contrasts with the human-interpretable, sparse information context which occurs in the context of the present study.

- Unsurprisingly, extensions, that is to say, coherent sets of arguments, can be interpreted as standpoints.

- Skeptically accepted arguments are consensual arguments, whereas credulously accepted arguments are dividing arguments.

- We introduced the concept of "strictly credulously accepted arguments" to denote arguments which are credulously but not skeptically accepted. These arguments correspond to divergences in the opinions. They are key features to understand the origin of divergent standpoints.

Concerning the case study, the following conclusions can be highlighted:

- Two standpoints can be distinguished in the system.

- Initial prejudices about short supply chains concerned mainly economic aspects, and secondarily technical aspects.

- Economic drawbacks are counterbalanced by benefits in other concerns.

- The social dimension is highly involved in the reevaluation of initial ideas. 
- The divergences between the two standpoints are all related to technical considerations, and more specifically to one technical argument about the logistical benefit of the device.

Several extensions to this work are considered, in a decision support perspective. One of them consists in taking into account other kinds of relations between arguments, such as specializations, expressing that some of them are particular cases or variations of others, as evoked in Section 3.2 of the paper. The consideration of such relations and their impact on the system are open questions. This paper illustrated how an argument may refine a previous one, in particular by considering more specialized hypotheses. In a complementary way, [7] considered the case where decisions may be more specialized than others. As an example, an argument giving a reason to support saltless bread with increased flour yield, decision denoted "F.Y \& Saltless", was considered as a specialization of the argument supporting the decision "F.Y.". This had consequences on the attack relation definition and on its symmetricity property. In the presence of specialized decisions, the attack relation is not symmetric: in [7] if a decision $d_{1}$ is more specialized than a decision $d_{2}$, then arguments supporting $d_{1}$ attack arguments supporting $d_{2}$ but the reverse attacks do not hold. On these bases, specialization may be exploited in decision support, such as policy making, in several directions: (i) for context-specific purposes, by refining recommended decisions according to the particular conditions considered, e.g. a given segment of the population, and (ii) for innovation, which is another promising use of specialization, through the invention of new options, namely specialized decisions, for mutual gain in a multi-actor context.

\section{References}

1. Amgoud, L., Ben-Naim, J., Vesic, S.: Measuring the intensity of attacks in argumentation graphs with shapley value. In: Proceedings of the Twenty-Sixth International Joint Conference on Artificial Intelligence, IJCAI-17, pp. 63-69 (2017)

2. Amgoud, L., Bodenstaff, L., Caminada, M., McBurney, P., Parsons, S., Prakken, H., Veenen, J., Vreeswijk, G.: Final review and report on formal argumentation system. Deliverable D2.6 ASPIC. Tech. rep. (2006)

3. Amgoud, L., Cayrol, C.: A reasoning model based on the production of acceptable arguments. Annals of Mathematics and Artificial Intelligence 34, 197-216 (2002)

4. Amgoud, L., Prade, H.: Using arguments for making and explaining decisions. Artificial Intelligence 173(3-4), 413-436 (2009)

5. Besnard, P., Hunter, A.: Elements of Argumentation. The MIT Press (2008)

6. Bonet, B., Geffner, H.: Arguing for decisions: A qualitative model of decision making. In: E. Horvitz, F. Jensen (eds.) Proc. 12th Conf. on Uncertainty in Artificial Intelligence, pp. 98-105. Morgan Kaufmann, Portland, OR (1996)

7. Bourguet, J.R., Thomopoulos, R., Mugnier, M.L., Abécassis, J.: An artificial intelligence-based approach to deal with argumentation applied to food quality in a public health policy. Expert Systems with Applications 40(11), 4539-4546 (2013)

8. Brewka, G., Gordon, T.F.: How to Buy a Porsche: An Approach to Defeasible Decision Making. In: Working Notes of the AAAI-94 Workshop on Computational Dialectics, pp. 28-38. Seattle, Washington (1994)

9. Chiffoleau, Y., Degenne, A.: Le développement des circuits courts à l'épreuve de l'analyse des réseaux sociaux. RES 68(4), 71-78 (2010)

10. Croitoru, M., Thomopoulos, R., Tamani, N.: A Practical Application of Argumentation in French Agrifood Chains, pp. 56-66. Springer International Publishing (2014)

11. Dung, P.M.: On the acceptability of arguments and its fundamental role in nonmonotonic reasoning, logic programming and $n$-person games. Artificial Intelligence Journal 77, 321-357 (1995)

12. Fox, J., Das, S.K.: Safe and sound - artificial intelligence in hazardous applications. MIT Press (2000)

13. Fox, J., Glasspool, D., Grecu, D., Modgil, S., South, M., Patkar, V.: Argumentation-based inference and decision making-a medical perspective 22, 34-41 (2007)

14. García, A.J., Simari, G.R.: Defeasible logic programming: An argumentative approach. Theory Pract. Log. Program. 4(2), 95-138 (2004) 
15. Gordon, T.F., Karacapilidis, N.: The Zeno Argumentation Framework. In: Proceedings of the Sixth International Conference on Artificial Intelligence and Law, pp. 10-18. ACM Press, Melbourne, Australia (1997)

16. Jarke, M., Jelassi, M., Shakun, M.F.: Mediator: Towards a negotiation support system. European Journal of Operational Research 31(3), 314 - 334 (1987)

17. Karacapilidis, N., Papadias, D.: Computer Supported Argumentation and Collaborative Decision Making: The HERMES System. Inf. Syst. 26(4), 259-277 (2001)

18. Kraus, S., Sycara, K.P., Evenchik, A.: Reaching agreements through argumentation: A logical model and implementation. Artif. Intell. 104(1-2), 1-69 (1998)

19. Mackenzie, J.: Begging the question in non-cumulative systems. Journal of Philosophical Logic 8, 117133 (1979)

20. Parsons, S., Fox, J.: Argumentation and decision making: A position paper, pp. 705-709. Springer Berlin Heidelberg, Berlin, Heidelberg (1996)

21. Paturel, D.: Alimentation et lien social : les circuits courts comme alternative ? RES 68(4), 41-45, 61-70 (2010)

22. Paturel, D., Demarque, F.: Approvisionnement local pour les restaurants du coeur de l'Hérault. Etude de faisabilité réalisée dans le cadre du PROA-LR. http://draaf.languedoc-roussillon. agriculture.gouv.fr/Un-approvisionnement-local-pour (2011)

23. Prakken, H.: An abstract framework for argumentation with structured arguments. Argument and Computation 1(2), 93-124 (2011)

24. Prakken, H., Sartor, G.: Law and logic: A review from an argumentation perspective 227 (2015)

25. Rahwan, I., Simari, G.R.: Argumentation in Artificial Intelligence. Springer (2009)

26. Rescher, N.: The role of rhetoric in rational argumentation. Argumentation 12(2), 315-323 (1997)

27. Sycara, K.P.: Persuasive argumentation in negotiation. Theory and Decision 28(3), 203-242 (1990)

28. Tamani, N., Mosse, P., Croitoru, M., Buche, P., Guillard, V., Guillaume, C., Gontard, N.: An argumentation system for eco-efficient packaging material selection. Computers and Electronics in Agriculture 113, 174-192 (2015)

29. Thomopoulos, R., Chadli, A., Croitoru, M., Abécassis, J., Brochoire, G., Chiron, H.: Information for decision-making is ubiquitous: Revisiting the reverse engineering mode in breadmaking technology. In: Research Challenges in Information Science (RCIS), 2015 IEEE 9th International Conference on, pp. 250-261. IEEE (2015)

30. Thomopoulos, R., Charnomordic, B., Cuq, B., Abécassis, J.: Artificial intelligence-based decision support system to manage quality of durum wheat products. Quality Assurance and Safety of Crops \& Foods 1(3), 179-190 (2009)

31. Thomopoulos, R., Croitoru, M., Tamani, N.: Decision support for agri-food chains: A reverse engineering argumentation-based approach. Ecological Informatics 26(2), 182-191 (2015)

32. Thomopoulos, R., Paturel, D., Quéré, S.: Un système d'argumentation avec contextes et indicateurs pour analyser un dispositif d'approvisionnement en circuit court. Research report (2013)

33. Tremblay, J., Abi-Zeid, I.: Value-based argumentation for policy decision analysis: methodology and an exploratory case study of a hydroelectric project in Québec. Annals of Operations Research pp. 1-21 (2015) 